\title{
UEFA 2016 Avrupa Futbol Şampiyonasındaki Şutların Pasların ve Oyun Geçişlerinin Analizi
}

\section{Murat YILDIZ1 ${ }^{1}$, Onur DEMIRARAR ${ }^{2}$, Aykut Eren CANÜZMEZ ${ }^{3}$, Bahtiyar ÖZÇALDIRAN ${ }^{4}$}

\begin{tabular}{lr} 
Özet & Anahtar Kelimeler \\
\hline Amaç: Bu çalışmanın amacı, UEFA 2016 Avrupa Futbol Şampiyonaşındaki maçların teknik & Teknik Analiz, \\
ve taktik analizini yapıp takımların başarı durumu üzerine etkilerini araştırmaktır. & Taktik Analiz, \\
Materyal ve Metot: Çalışmamızın örneklemi; şampiyonadaki 51 maçtan oluşmaktadır. Maç & Maç Analizi, \\
sonuçları başarılı (n=56) ve başarısı (n=46) olarak ayrılmıştır. Teknik parametre verileri için & Defansif Geçişler, \\
OPTA Sportsdata ve Euro 2016 sitesinden, taktik parametre verileri için ise LongoMatch & Ofansif Geçisler, \\
v.0.20.8 video analiz programından yararlanıldı. Verilerin analizinde, IBM SPSS v.21.0 & Oyun Tarzları.
\end{tabular}

kullanıldı ve nonparametrik Ki-kare $\left(\mathrm{X}^{2}\right)$ bağımsızlık testinden yararlanıldı.

Bulgular: Ceza sahası içinden atılan isabetli şutlar, üçüncü bölgedeki isabetli uzun paslar, ikinci bölgede kayıp sonrası üçüncü bölgede 0-5 sn. içinde kazanılan toplar, birinci bölgede 510 sn. içinde geri kazanılan toplar, birinci bölgede kazanılan topla 0-10 sn. içerisinde karş1 yarı alana geçişler, rakip yarı alan ikinci bölgede kazanılan topla 0-5 sn. ve 5-10 sn.'de isabetli şutla sonuçlanan ataklar ile başarılı maç sonuçları arasında istatistiksel olarak anlamlı ilişki bulunmuștur $(\mathrm{p}<0.05)$. Üçüncü bölgedeki tüm isabetsiz paslar, birinci bölgedeki isabetli uzun paslar, ikinci bölgeden üçüncü bölgeye isabetsiz uzun paslar, isabetsiz kısa paslar ve rakip yarı alanda oyunun yönünü soldan sağa değiştiren isabetsiz paslar ile başarısız maç sonuçları arasında istatistiksel olarak anlamlı ilişki bulunmuştur $(\mathrm{p}<0.05)$.

Sonuç: Sonuç olarak; defansif ve ofansif geçişlerde $0-5$ ve 5-10 sn. de reaksiyon gösteren, üçüncü bölgede isabetli uzun pas yapan, atakları ceza sahası içerisinde isabetli şutla sonuçlandıran takımlar başarılı sonuçlar alabilmektedirler.

\section{Analysis of Shots Passing and Transitions in the UEFA 2016 European Football Championship}

\section{Abstract}

Aim: The aim of this study is to analyze the technical and tactical analysis of the matches in the UEFA 2016 European Football Championship and to investigate the effects of the teams on their success status.

Methods: The sample of our study consists of 51 matches played in the championship. The match results were divided into two as successful $(n=56)$ and unsuccessful $(n=46)$. OPTA Sportsdata and Euro 2016 website were used for technical parameter data, and LongoMatch v.0.20.8 video analysis program was used for tactical parameter data. For statistical analysis of the data, nonparametric Chi-square $\left(\mathrm{X}^{2}\right)$ independence test was used with IBM SPSS v.21.0. Results: A statistically significant correlation has been found between the successful results of the teams and shots on target from inside the penalty area, successful long passes in the third zone, balls recovered within $0-5 \mathrm{sec}$. in the third zone after loss in the second zone, balls recovered within 5-10 sec. in the first zone, transitions to the opposite half field within 0-10 seconds with the ball won in the first zone, attacks resulting in shots on target within 0-5 and $5-10 \mathrm{sec}$. after the ball is won in the second zone of the opponent's half field $(\mathrm{p}<0.05)$. A statistically significant correlation has been found between the unsuccessful results of the teams and all unsuccessful passes in the third zone, successful long passes in the first zone, unsuccessful long passes from the second zone to the third zone, unsuccessful short passes, unsuccessful passes that change the direction of the game from left to right on the opponent's half field $(\mathrm{p}<0.05)$.

Conclusion: As a result, teams that react in 0-5 and 5-10 sec. during defensive and offensive transitions, make successful long passes in the third zone, and finish the attacks with shots on target in the penalty area can achieve successful results.
Keywords

Technical analysis,

Tactical Analysis,

Match Analysis,

Defensive Transitions,

Ofensive Transitions, Game Styles.

Article Info

Received: 04.05.2021

Accepted: 30.08 .2021

Online Published: 15.09 .2021

DOI: $10.18826 /$ useeabd.930133

The role and contributions of each authors as in the section of IJSETS Writing Rules "Criteria for Authorship" is reported that: 1. Author: Contributions to the conception or design of the paper, data collection, statistical analysis, interpretation of the data, writing of the paper; 2 . Author: Design of the paper, writing of the paper, statistical analysis; 3. Author:, Contributions to the conception of the paper, final approval of the version to be published paper; 4 . Author: Preparation of the paper according to rules of the journal and final approval of the version to be published paper.

${ }^{1}$ Corresponding Author: Department of Sports and Health Sciences, Ege University, Izmir/Turkey, yldzmrt90@gmail.com ORCID ID: 0000-0002-1684-1889 2Department of Sports and Health Sciences, Ege University, Izmir/Turkey, onurdemirarar@gmail.com ORCID ID: 0000-0002-2421-0067

${ }^{3}$ Deparment of Coaching Education, Ege University, Izmir/Turkey, aykut.eren.canuzmez@ege.edu.tr ORCID ID: 0000-0002-2908-2850

${ }^{4}$ Department of Movement and Training Sciences, Ege University, Izmir/Turkey, bahtivarozcaldiran@gmail.com ORCID ID: 0000-0002-9724-6730 


\section{GİRIŞ}

Futbolda performans farkl1 teknik, taktik, fiziksel, zihinsel (Carling vd., 2005) ve fizyolojik faktörlerin etkileşimine bağlıdır (Coutts, 2014; Bangsbo vd., 2006; Bradley vd., 2009; Mohr vd., 2003). Bilgisayar destekli sistemlerin kullanımıyla; maç öncesi, maç esnası ve maç sonrasında sporcuların teknik, taktik, fiziksel ve davranışsal performansları hakkında verileri toplamak mümkündür (Carling vd., 2005; Baca, 2014). Yapılan araştırmalarda, antrenörler tarafından maç esnasında gözlemlenen eylemlerin sadece $\% 42$ veya \%59'nun hatırlandığı ve bu oranların oyuncuların performanslarına yönelik verilen geribildirimin sınırlı olmasına neden olduğu görülmüştür (Franks \& Miller, 1986; Laird \& Waters, 2008). Sporcuların performanslarının gelişimi için geri bildirimde bulunmak antrenörlük sürecinin önemli bir parçasıdır (Maslovat \& Franks, 2008). Bu bağlamda, teknik ekibe dahil olan maç analistleri elde ettikleri objektif verileri, sporcular ve antrenörler ile paylaşarak takım başarısına katkıda bulunurlar.

Modern futbolda oyun geçişleri önemli bir yer tutmaktadır ve takımlarının benimsedikleri oyun stillerini sahaya yansitarak, topla veya topsuz şekilde savunmadan hücuma, hücumdan savunmaya belli bir süre içerisinde hareket etmeleri anlamını taşımaktadır. Bu yaklaşımı kullanan futbol takımları topu geri kazanmaya odaklanır ve topu kazandıklarında ise oyun planlarına uygun olarak hedefe doğru hareket ederler (Bangsbo \& Peitersen, 2016).

Futbolun bu kompleks yapısını anlayabilmek yapılan birkaç önemli çalışmada genel olarak incelenen teknik, taktik ve fiziksel performans parametreleri; paslar, ortalar, şutlar, top kayıpları, top kapmalar, top kazanımları, topa temas sayıları, duran toplar, topa sahip olma, topa sahip olma süreleri, goller, defansif reaksiyon süreleri, geçişler, kontra atak sayıları, kontra atak süreleri, düşük yoğunluklu koşular, yüksek yoğunluklu koşular, sprint mesafeleri, koşu hızları ve kat edilen mesafeler şeklindedir (Tenga vd., 2010a; Scoulding vd., 2004; Hughes \& Churchill, 2005; Barreira vd., 2014; De Baranda \& Lopez-Riquelme, 2012; Jones vd., 2004; Vogelbein vd., 2014; Barnes vd., 2014; Hughes \& Franks, 2005). Maç performansı analizlerinde kriter olarak gol parametresinin üzerinde çok durulmuştur (Carling vd., 2005; Hughes \& Franks, 2005; Tenga vd., 2010b). Fakat sadece gollerin analiziyle futboldaki başarıyı açıklamak yeterli olmayacaktır.

Bir takımın başarı elde etmesi için koşu mesafeleri vb. diğer fiziksel performans göstergeleri önemli veri kaynağı olabilir. Ancak, takım olarak defansif ve ofansif anlamda doğru pozisyon alınmıyorsa ya da bölgeler arası oyun geçişleri zamanında gerçekleşmiyorsa, elde edilen sonuç sadece fiziksel performans göstergeleri ile ilişkilendirilmemelidir. Dolayısıyla futbolda başarı veya golün oluşumuna etki eden faktörler teknik, taktik ve fiziksel açıdan her yönüyle analiz edilmelidir. Bu sebeplerden dolayı araştırmamızın amacı, UEFA 2016 Avrupa Futbol Şampiyonasındaki oyun geçişlerinin, pasların ve şutların, takımların başarı durumları üzerine etkilerinin incelenmesidir. Araştırmamızın bulgu ve sonuçlarının kritik önemi, teknik ve taktik yönden defansif ve ofansif oyun geçişlerinin önemini ortaya koyarken futbolun dinamik yapısına 1şık tutacaktır.

\section{MATERYAL ve YÖNTEM}

\section{Katılımcılar}

Araştırmanın katılımcıları UEFA Avrupa 2016 şampiyonasında yer alan 24 profesyonel milli takımın, şampiyonada oynadığ 51 maçtan oluşmaktadır. Turnuvadaki maçlar, takımların başarılı $(\mathrm{n}=56)$ ve başarısız $(\mathrm{n}=46)$ maç sonuçları olmak üzere ikiye ayrılmıştır. Başarılı maç sonuçları; takımların galibiyet, beraberlik ve üst tura çıkmaları ile, başarısız maç sonuçlarıysa; takımların mağlubiyetleri, beraberlikleri ve üst tura çıkamamaları ile nitelendirildi.

Etik Kurul Onayı: Çalışmamıza Ege Üniversitesi Rektörlüğü, Sağlık Bilimleri Bilimsel Araştırma ve Yayın Etiği Kurulu'nun 19.01.2018 tarihli toplantıs1 sonucu, 401-2017 protokol no'lu belgesiyle araştırma için gerekli izin ve onay alınmıştır.

Araştırma Tasarımı: Araştırma tasarımında, sistematik gözlemlere dayalı olan teknik ve taktik parametrelerin incelenmesi için tanımlayıcı araştırma tipi kullanıldı. Randomizasyon metodu olarak tabakalı (stratified) randomizasyon kullanıldı.

Araştırmada Kullanılan Gereçler: Teknik parametrelerin verilerinin toplanması ve değerlendirilmesi için gerçek zamanlı veri akışı sağlayan OPTA Sportsdata firması ile UEFA Euro 2016 web sitesinden yararlanıldı. Ulusal yayıncı kuruluş tarafından yayınlanan maç görüntüleri, BandiCam 4.0.2.1352 versiyon video kayıt programıyla maçlar yayınlandığı esnada bilgisayar ortamında kaydedildi. Taktik 
parametre verilerinin toplanması ve değerlendirilmesinde ise bilgisayar destekli LongoMatch 0.20.8 sürümü açık kaynak video maç analiz programı kullanıldı.

Video Analiz Yöntemi: Araştırmada gözlemsel ve bilgisayar yardımlı notasyon analizi yöntemi kullanıldı. Maçların analizleri LongoMatch programı kullanılarak maç sonrasında yapıldı. Şampiyonada gruplardaki 24 takım ile son 16'ya ve finallere kalan takımların maçları teknik ve taktik açıdan analiz edilmiştir. Grup aşamasında toplam 36, eleme aşamasında (son 16, çeyrek final, yarı final ve final) toplam 15 maç oynandı ve analiz edildi. Maçların analizinde, futbol sahaları figür-1'de görüldüğü gibi üç eşit bölgeye ayrılarak veriler toplandı. Veriler 15 'şer dakikalık dilimlere ayrılarak toplandı ve duraklama dakikaları da dahil olmak üzere 90 dakikalık kısım analiz edildi. Toplanan ham veriler Microsoft Office Excell Pro Plus 2016 programında işlendi.

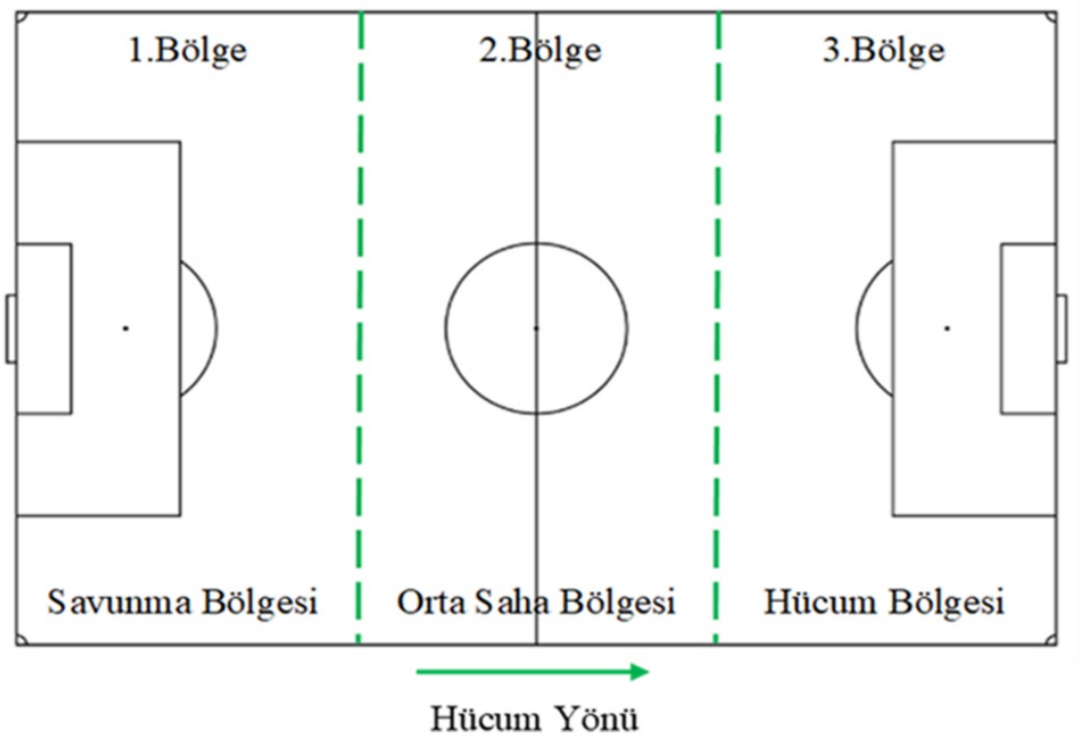

Figür-1: Futbol Sahasının Bölümleri

\section{İstatiksel Analiz}

Taktik parametrelerin güvenilirliğinde, iki gözlem arasındaki uyumun güvenilirliğini değerlendirmek için Altman'ın (1991) oluşturduğu; mükemmel uyum 0.81-1.00, iyi derecede uyum 0.61-0.80, orta derecede uyum 0.41-0.60, az uyum 0.21-0.40, zayıf uyum $<0.20$ kappa değerlerinden

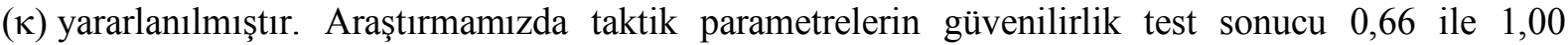
$\kappa$ arasında bulunmuştur (Tablo-1). Teknik parametrelerle ilgili, OPTA Sportsdata şirketinin futbol maç istatistiklerinin güvenilirlik testi yapılmış ve bu izleme sistemi ile toplanan verilerin güvenilirlik test sonuçları mükemmel uyum 0.92-0.94 $\kappa$ seviyesinde çıkmıştır (Liu vd., 2013). Grup aşamasında ve eleme aşamasında, takımların başarıyla ve başarısızlıkla sonuçlanan maçlarını kıyaslamak ve performans göstergeleri ile başarı durumu arasında ilişki olup olmadığını ortaya çıkarmak için ShapiroWilk normallik testi yapıldı ve verilerin normal dağılmadığı bulundu ( $>0.05)$. Bu nedenle nonparametrik testlerden Ki-kare $\left(\mathrm{X}^{2}\right)$ bağımsızlık testi kullanıldı. Verilerin istatistiksel analizi için IBM SPSS 21.0 versiyon istatistik paket programı kullanılmıştır. İstatistiksel anlamlılık düzeyi $p<0.05$ olarak kabul edilmiştir.

Tablo 1. Taktik Verilerin Gözlemci-Içi Güvenilirlik Testi Kappa Test Sonuçları

\begin{tabular}{|lc|}
\hline \multicolumn{1}{|c|}{ Taktik Parametreler } & א \\
\hline Top Kaybından Sonra Yapılan Pres ile Topun Geri Kazanılma Sayısı ve Süresi & 0.70 \\
\hline Kendi Yarı Alanında Top Kazanma ve Karşı Alana Geçme Sayısı ve Süresi & 0.66 \\
\hline Karşı Yarı Alanda Top Kazanma ve Atağı Sonuçlandırma Sayısı ve Süresi & 1.00 \\
\hline
\end{tabular}

\section{BULGULAR}

\section{Şutların ve Pasların Analizi}

Turnuvada yer alan takımların farklı bölgelerden ilk yarı, ikinci yarı ve uzatmalarda kullandıkları şut isabetine ilişkin verilere göre, sadece ceza sahası içinden atılan isabetli şutlar ile takımların başarılı maç sonuçları arasında, istatistiksel olarak anlamlı bir ilişki olduğu $(\mathrm{p}<0.05)$ görülmüştür $($ Tablo-2). Altı 
pas, ceza sahası içi ve ceza sahası dışında kullanılan isbetsiz şutlar ile, altı pas ve ceza sahası dışından kullanılan isabetli şutlar ile takımların başarı ya da başarısızlık sonuçları arasında istatistiksel olarak anlamlı bir ilişki ( $>0.05)$ bulunmamıştır (Tablo-2).

Tablo 2. Takımların Oyun Süresi Boyunca Çeşitli Bölgelerden Kullandıkları Şut Parametrelerinin Ki-Kare Test Sonuçları.

\begin{tabular}{|c|c|c|c|c|}
\hline \multirow{5}{*}{ 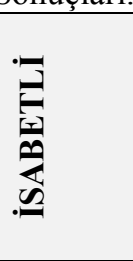 } & \multirow[t]{2}{*}{ Şut Parametreleri } & $\begin{array}{c}\text { Başarilı } \\
(\mathrm{n}=56)\end{array}$ & \multicolumn{2}{|l|}{$\begin{array}{c}\text { BaşarısıIZ } \\
(\mathrm{n}=46)\end{array}$} \\
\hline & & Ort. \pm SS. & Ort. \pm SS. & $\mathbf{p}$ \\
\hline & 6 Pas & $0.34 \pm 0.70$ & $0.17 \pm 0.44$ & 0.333 \\
\hline & Ceza Sahası İçi & $3.04 \pm 1.85 *$ & $1.52 \pm 1.41$ & 0.001 \\
\hline & Ceza Sahası Dıșı & $1.75 \pm 1.54$ & $1.24 \pm 1.20$ & 0.136 \\
\hline \multirow{3}{*}{ 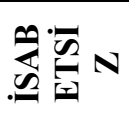 } & 6 Pas & $0.23 \pm 0.47$ & $0.24 \pm 0.48$ & 0.912 \\
\hline & Ceza Sahası İçi & $3.30 \pm 2.12$ & $2.43 \pm 1.96$ & 0.148 \\
\hline & Ceza Sahası Dıșı & $2.55 \pm 1.78$ & $2.52 \pm 1.71$ & 0.695 \\
\hline
\end{tabular}

Ort. \pm SS: Ortalama \pm Standart Sapma. n: Gruptaki örneklem say1sı. *: $\mathrm{p}<0.05$

Turnuvada yer alan takımların farklı bölgelerde ilk yarı, ikinci yarı ve uzatmalarda kullandıkları çeşitli pas türlerine ilişkin verilere göre, birinci bölge içinde isabetli uzun pasların, takımların başarısız maç sonuçları ile istatistiksel olarak anlamlı bir ilişkisinin olduğu $(\mathrm{p}<0.05)$, üçüncü bölge içinde isabetli uzun pasları ise takımların başarılı maç sonuçları ile istatistiksel olarak anlamlı bir ilişkisinin olduğu $(\mathrm{p}<0.05)$ görülmüştür (Tablo-3). Üçüncü bölgedeki tüm isabetsiz paslar, ikinci bölgeden üçüncü bölgeye atılan isabetsiz uzun paslar, isabetsiz kısa paslar ve rakip yarı alanda oyunun yöünün soldan sağa değiştiren isabetsiz paslar ile takımların başarısız maç sonuçları arasında istatistiksel olarak anlamlı bir ilişki olduğu $(\mathrm{p}<0.05)$ saptanmıştır $($ Tablo-3). Bunların dışında kalan tüm parametreler ile takımların başarı ya da başarısızlıkla ilişkisi arasınada istatsitiksel olarak anlamlı bir ilişki ( $\mathrm{p}>0.05)$ bulunamamışır (Tablo-3).

Tablo 3. Takımların Oyun Süresi Boyunca Çeşitli Pas Parametrelerinin Ki-Kare Test Sonuçları.

\begin{tabular}{|c|c|c|c|c|}
\hline & Pas Parametreleri & $\begin{array}{c}\text { Başarılı } \\
(\mathrm{n}=56)\end{array}$ & $\begin{array}{c}\text { Başarısız } \\
(\mathrm{n}=\mathbf{4 6})\end{array}$ & \\
\hline & & Ort. \pm SS. & Ort. \pm SS. & $\mathbf{p}$ \\
\hline & 1. Bölgedeki Tüm Paslar & $64.39 \pm 22.89$ & $70.50 \pm 26.74$ & 0.598 \\
\hline & 2. Bölgedeki Tüm Paslar & $205.63 \pm 84.97$ & $198.72 \pm 79.77$ & 0.691 \\
\hline & 3. Bölgedeki Tüm Paslar & $91.23 \pm 54.77$ & $82.20 \pm 40.342$ & 1 \\
\hline & Uzun Pas - 1. Bölge İçinde & $0.95 \pm 1.31$ & $1.11 \pm 1.12^{*}$ & 0.007 \\
\hline & Uzun Pas - 1. Bölgeden 2. Bölgeye & $6.96 \pm 3.95$ & $6.80 \pm 3.83$ & 0.949 \\
\hline & Uzun Pas - 1. Bölgeden 3. Bölgeye & $1.80 \pm 1.91$ & $2.39 \pm 2.59$ & 0.976 \\
\hline & Uzun Pas - 2. Bölge İçinde & $3.79 \pm 2.67$ & $3.91 \pm 2.73$ & 0.099 \\
\hline 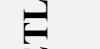 & Uzun Pas - 2. Bölgeden 1. Bölgeye & $1.18 \pm 1.35$ & $1.37 \pm 1.24$ & 0.253 \\
\hline 䆓 & Uzun Pas - 2. Bölgeden 3. Bölgeye & $6.20 \pm 3.29$ & $5.96 \pm 3.53$ & 0.778 \\
\hline జ & Uzun Pas - 3. Bölge İçinde & $0.95 \pm 1.09^{*}$ & $0.65 \pm 1.27$ & 0.018 \\
\hline & Uzun Pas - 3. Bölgeden 2. Bölgeye & $0.23 \pm 0.47$ & $0.15 \pm 0.47$ & 0.113 \\
\hline & Uzun Pas - 3. Bölgeden 1. Bölgeye & $0 \pm 0^{\mathrm{a}}$ & $0 \pm 0^{\mathrm{a}}$ & - \\
\hline & Kisa Pas & $341.11 \pm 138.17$ & $328.96 \pm 122.35$ & 0.233 \\
\hline & İleriye doğru Pas & $178.52 \pm 69.18$ & $171.52 \pm 60.11$ & 1 \\
\hline & Geriye Doğru Pas & $105.04 \pm 40.85$ & $106.89 \pm 37.09$ & 1 \\
\hline & Yana Doğru Pas & $78.48 \pm 35.76$ & $72.93 \pm 32.21$ & 0.970 \\
\hline & $\begin{array}{l}\text { Rakip Yarı Alanda OyunYönü } \\
\text { Değiștirme - Sağdan Sola Pas }\end{array}$ & $7.91 \pm 5.80$ & $6.96 \pm 4.97$ & 0.205 \\
\hline & $\begin{array}{l}\text { Rakip Yarı Alanda OyunYönü } \\
\text { Değiștirme - Soldan Sağa Pas }\end{array}$ & $8.18 \pm 5.99$ & $7.76 \pm 6.02$ & 0.573 \\
\hline & 1. Bölgedeki Tüm Paslar & $5.32 \pm 2.87$ & $5.59 \pm 3.16$ & 0.802 \\
\hline & 2. Bölgedeki Tüm Paslar & $37.95 \pm 10.10$ & $37.33 \pm 8.64$ & 0.802 \\
\hline$N$ & 3. Bölgedeki Tüm Paslar & $38.82 \pm 10.63$ & $44.15 \pm 8.61^{*}$ & 0.001 \\
\hline 芯 & Uzun Pas - 1. Bölge İçinde & $0.20 \pm 0.44$ & $0.17 \pm 0.44$ & 0.886 \\
\hline & Uzun Pas - 1. Bölgeden 2. Bölgeve & $9.88 \pm 4.87$ & $9.85 \pm 5.53$ & 0.705 \\
\hline
\end{tabular}




\begin{tabular}{|l|lcc|}
\hline Uzun Pas - 1. Bölgeden 3. Bölgeye & $5.38 \pm 4.86$ & $5.41 \pm 4.25$ & 0.573 \\
Uzun Pas - 2. Bölge İçinde & $0.52 \pm 0.69$ & $0.39 \pm 0.61$ & 0.588 \\
Uzun Pas - 2. Bölgeden 1. Bölgeye & $0.05 \pm 0.23$ & $0.02 \pm 0.15$ & 0.349 \\
Uzun Pas - 2. Bölgeden 3. Bölgeye & $7.00 \pm 3.38$ & $8.98 \pm 3.87^{*}$ & $\mathbf{0 . 0 0 1}$ \\
Uzun Pas - 3. Bölge İçinde & $0.63 \pm 0.86$ & $0.80 \pm 0.89$ & 0.217 \\
Uzun Pas - 3. Bölgeden 2. Bölgeye & $0,02 \pm 0,134$ & $0 \pm 0^{\mathrm{a}}$ & 0.361 \\
Uzun Pas - 3. Bölgeden 1. Bölgeye & $0 \pm 0^{\mathrm{a}}$ & $0 \pm 0^{\mathrm{a}}$ & - \\
Kisa Pas & $59.21 \pm 9.35$ & $61.33 \pm 11.01^{*}$ & $\mathbf{0 . 0 2 4}$ \\
İleriye doğru Pas & $64.54 \pm 16.16$ & $69.22 \pm 12.54$ & 0.826 \\
Geriye doğru Pas & $4.27 \pm 3.77$ & $3.91 \pm 2.22$ & 0.778 \\
Yana Doğru Pas & $13.48 \pm 4.58$ & $13.39 \pm 4.12$ & 0.856 \\
Rakip Yarı Alanda OyunYönü & $5.09 \pm 3.03$ & $4.43 \pm 2.94$ & 0.573 \\
Değiștirme - Sağdan Sola Pas & & & $\mathbf{0 . 0 0 5}$ \\
Rakip Yarı Alanda OyunYönü & $4.00 \pm 2.80$ & $5.11 \pm 2.67 *$ & \\
Değiștirme - Soldan Sağa Pas & & & \\
\hline
\end{tabular}

Ort. \pm SS: Ortalama \pm Standart Sapma. a: Kayda değer veriye rastlanmadığı için gruplar arasında kıyaslama yapılamaz. n: Gruptaki örneklem say1s1. *: $\mathrm{p}<0.05$

\section{Taktik Analiz}

UEFA 2016 Avrupa Futbol Şampiyonasındaki maçlarda, takımların top kaybından sonra yapılan pres ile $10 \mathrm{sn}$. içinde topun geri kazanılma sayı ve süresiyle alakalı verilere bakıldığında, ikinci bölgede kaybedilip, üçüncü bölgede 0-5 sn. içinde geri kazanılan toplar ve birinci bölgede kaybedilip, birinci bölgede 5-10 sn. içinde geri kazanılan toplar ile takımların başarılı maç sonuçları arasında istatistiksel olarak anlamlı bir ilişki olduğu $(\mathrm{p}<0.05)$ saptandı (Tablo-4). Takımların kendi yarı alanlarında topu kazanarak karşı yarı alana geçme sayısına ve süresiyle ilgili verilere bakıldığında, topun birinci bölgede kazanılarak 0-10 sn. içerisinde karşı yarı alana yapılan geçişler ile takımların başarılı maç sonuçları arasında istatistiksel olarak anlamlı bir ilişki olduğu $(\mathrm{p}<0.05)$ gözlemlenmiştir (Tablo-4). Ayrıca takımların karşı yarı alanda top kazandıktan sonra atağı $10 \mathrm{sn}$. içerisinde sonuçlandırma sayısına ve süresine ilişkin verilere bakıldığında, sadece topun rakip yarı alan ikinci bölgede kazanılarak 0-5 sn. ve 5-10 sn. içerisinde isabetli şutla sonuçlanan ataklar ile takımların başarılı maç sonuçları arasında istatistiksel olarak anlamlı bir ilişki olduğu $(\mathrm{p}<0.05)$ bulunmuştur $($ Tablo-4). Bunların dışında kalan tüm taktik parametreler ile takımların başarı ya da başarısızlıkla ilişkileri arasında istatistiksel olarak anlamlı bir ilişki ( $\mathrm{p}>0.05)$ görülmemiştir (Tablo-4).

Tablo 4. Takımların Oyun Süresi Boyunca Çeşitli Bölgelerde Oynadıkları Çeşitli Taktik Süre ve Sayı Parametrelerinin Ki-Kare Test Sonuçları.

\begin{tabular}{|c|c|c|c|c|}
\hline \multirow{2}{*}{\multicolumn{2}{|c|}{ Taktik Parametreler }} & $\begin{array}{c}\text { Başarılı } \\
(\mathrm{n}=56)\end{array}$ & $\begin{array}{c}\text { Başarısız } \\
(n=46)\end{array}$ & \\
\hline & & Ort. \pm SS. & Ort. \pm SS. & p \\
\hline \multirow{18}{*}{$\begin{array}{c}\text { TOP KAYBINDAN SONRA } \\
\text { YAPILAN PRES İLE TOPUN GERI } \\
\text { KAZANILMASI }\end{array}$} & 1. Bölge_1. Bölge (0-5 sn.) & $0.27 \pm 0.52$ & $0.17 \pm 0.38$ & 0.948 \\
\hline & 1. Bölge_2. Bölge (0-5 sn.) & $0 \pm 0^{\mathrm{a}}$ & $0 \pm 0^{\mathrm{a}}$ & - \\
\hline & 1. Bölge_3. Bölge (0-5 sn.) & $0 \pm 0^{\mathrm{a}}$ & $0 \pm 0^{\mathrm{a}}$ & - \\
\hline & 2. Bölge 1 . Bölge $(0-5 \mathrm{sn}$.) & $0.50 \pm 0.76$ & $0.35 \pm 0.60$ & 0.261 \\
\hline & 2. Bölge_2. Bölge (0-5 sn.) & $2.52 \pm 1.97$ & $2.17 \pm 1.48$ & 0.903 \\
\hline & 2. Bölge_3. Bölge (0-5 sn.) & $0.18 \pm 0.43 *$ & $0.02 \pm 0.15$ & 0.002 \\
\hline & 3. Bölge_1. Bölge (0-5 sn.) & $0.05 \pm 0.23$ & $0.07 \pm 0.25$ & 0.936 \\
\hline & 3. Bölge_2. Bölge (0-5 sn.) & $1.93 \pm 1.68$ & $2.26 \pm 1.48$ & 0.428 \\
\hline & 3. Bölge_3. Bölge $(0-5 \mathrm{sn}$.) & $1.57 \pm 1.48$ & $1.39 \pm 1.09$ & 0.798 \\
\hline & 1. Bölge_1. Bölge (5-10 sn.) & $0.20 \pm 0.40^{*}$ & $0.02 \pm 0.15$ & 0.001 \\
\hline & 1. Bölge_2. Bölge (5-10 sn.) & $0.04 \pm 0.19$ & $0.02 \pm 0.15$ & 0.837 \\
\hline & 1. Bölge_3. Bölge (5-10 sn.) & $0 \pm 0^{\mathrm{a}}$ & $0 \pm 0^{\mathrm{a}}$ & - \\
\hline & 2. Bölge_1. Bölge (5-10 sn.) & $0.84 \pm 0.97$ & $0.85 \pm 0.94$ & 0.829 \\
\hline & 2. Bölge_2. Bölge (5-10 sn.) & $1.89 \pm 1.66$ & $1.61 \pm 1.24$ & 0.748 \\
\hline & 2. Bölge_3. Bölge (5-10 sn.) & $0.07 \pm 0.26$ & $0.15 \pm 0.42$ & 0.403 \\
\hline & 3. Bölge_1. Bölge (5-10 sn.) & $0.50 \pm 0.76$ & $0.26 \pm 0.49$ & 0.147 \\
\hline & 3. Bölge_2. Bölge (5-10 sn.) & $2.70 \pm 2.07$ & $2.87 \pm 1.85$ & 0.086 \\
\hline & 3. Bölge 3. Bölge (5-10 sn.) & $0.64 \pm 0.90$ & $0.57 \pm 0.72$ & 0.638 \\
\hline
\end{tabular}




\begin{tabular}{|c|c|c|c|c|c|}
\hline \multicolumn{2}{|c|}{$\begin{array}{l}\text { KENDİ YARI ALANINDA TOP } \\
\text { KAZANMA VE KARŞI ALANA } \\
\text { GEÇME }\end{array}$} & $\begin{array}{l}\text { 1.Bölge (0-10 sn.) } \\
\text { 2.Bölge (0-10 sn.) }\end{array}$ & $\begin{array}{c}12.93 \pm 4.31^{*} \\
11.82 \pm 4.49\end{array}$ & $\begin{array}{l}11.52 \pm 2.73 \\
11.15 \pm 4.68\end{array}$ & $\begin{array}{l}\mathbf{0 . 0 0 1} \\
0.528\end{array}$ \\
\hline \multirow{8}{*}{$\begin{array}{c}\text { KARŞI YARI } \\
\text { ALANDA TOP } \\
\text { KAZANMA VE } \\
\text { ATAĞI } \\
\text { SONUÇLANDIRMA }\end{array}$} & \multirow{4}{*}{ 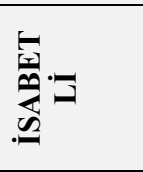 } & 2.Böl. (0-5 sn.) & $0.16 \pm 0.42 *$ & $0.07 \pm 0.33$ & 0.023 \\
\hline & & 3.Böl. (0-5 sn.) & $0.05 \pm 0.23$ & $0.04 \pm 0.21$ & 0.774 \\
\hline & & 2.Böl. (5-10 sn.) & $0.16 \pm 0.37^{*}$ & $0.04 \pm 0.21$ & 0.049 \\
\hline & & 3.Böl. (5-10 sn.) & $0.04 \pm 0.19$ & $0.00 \pm 0.00$ & 0.130 \\
\hline & \multirow{4}{*}{$\sum_{\mathscr{N}}^{\mathscr{n}} \cdot \frac{N}{\sigma}$} & 2.Böl. (0-5 sn.) & $0.07 \pm 0.26$ & $0.11 \pm 0.32$ & 0.804 \\
\hline & & 3.Böl. (0-5 sn.) & $0.05 \pm 0.23$ & $0.11 \pm 0.32$ & 0.550 \\
\hline & & 2.Böl. (5-10 sn.) & $0.09 \pm 0.29$ & $0.07 \pm 0.25$ & 0.550 \\
\hline & & 3.Böl. (5-10 sn.) & $0.07 \pm 0.26$ & $0.02 \pm 0.15$ & 0.421 \\
\hline
\end{tabular}

Ort. \pm SS: Ortalama \pm Standart Sapma. a: Kayda değer veriye rastlanmadığı için gruplar arasında kıyaslama yapılamaz. n: Gruptaki örneklem sayıs1. *: $p<0.05$

\section{TARTIŞMA}

Bu araştırmada, UEFA 2016 Avrupa Futbol Şampiyonası'ndaki şut, pas ve taktik parametrelerin maç sonuçlarına göre belirlenen başarı durumu üzerine etkisi incelendi. Bu amaçla hipotezlerimiz; a) Hücum bölgesinin farklı alanlarında gerçekleşen şut etkinliklerinin maçlarda başarı durumuna etkisi vardır, b) Pas etkinliklerinin maçlarda başarı durumuna etkisi vardır, c) Defansif oyun geçişlerinin maçlarda başarı durumuna etkisi vardır, d) Ofansif oyun geçişlerinin maçlarda başarı durumuna etkisi vardır olarak belirlendi.

Bulgularımıza göre ceza sahası içinden atılan isabetli şutların $(\mathrm{p}=0.001)$ maçlarda başarılı olma kriteri ile anlamlı bir ilişkisi vardır. Ofansif geçişleri doğru pozisyon alarak kısa sürede gerçekleştiren oyuncular, ceza sahası içerisinden isabetli şut atacak organizasyonlar yaratarak atağı sonuçlandırırlar. Literatüre baktığımızda bir araştırmada, kazanan takımların berabere kalan ve kaybeden takımlara göre daha fazla isabetli şut atıldığı tespit edilmiştir (Lago- Peñas vd., 2011). UEFA Avrupa 2012'deki maçlarda ceza sahası içinden çekilen şutlar $(\mathrm{p}=0.001)$, kazananlar ve kaybedenler arasında önemli bir fark yaratmıştır (Muhamad vd., 2013).

Araştırmamızda üçüncü bölge içindeki isabetli uzun pasların $(\mathrm{p}=0.018)$, takımların başarılı olma durumu ile arasında anlamlı ilişki bulunmuştur. Birinci bölge içinde atılan isabetli uzun pasların $(\mathrm{p}=0.007)$, üçüncü bölgedeki isabetsiz tüm pasların $(\mathrm{p}=0.001)$, ikinci bölgeden üçüncü bölgeye atılan isabetsiz uzun pasların ( $\mathrm{p}=0.001)$, isabetsiz kısa pasların $(\mathrm{p}=0.024)$, rakip yarı alanda oyunun yönünü soldan sağa değiştirmek için atılan isabetsiz pasların $(\mathrm{p}=0.005)$ maçlarda başarısız olma kriteri ile anlamlı ilişkisi bulunmaktadır. Üçüncü bölgede dış koridor ve iç koridordan atılan isabetli uzun paslar, hücumda oyun genişliği sağlayıp defansın yapısını bozduğundan dolayı etkili atak geliştirmede avantaj sağlar. Birinci bölgede atılan isabetli uzun paslar top kaybı için risk yaratır. Üçüncü bölgedeki isabetsiz tüm paslar ve ikinci bölgeden üçüncü bölgeye atılan isabetsiz uzun paslar kontra atak için rakibe fırsat verir. İsabetsiz kısa paslar ve soldan sağa oyun yönünü değiştiren isabetsiz paslar oyunun dinamik yapısını olumsuz etkiler.

Barnes ve diğerlerinin (2014) yaptığı bir araştırmada, son zamanlarda İngiliz Premier Ligi'nde sezonlar arasındaki kısa ve orta pas uzunluğundaki artışın pas temposunu arttırdığı tespit edilmiş ve buradan yola çıkarak uzun paslara oranla daha yüksek isabet oranına sahip olan kısa ve orta uzunluktaki pasların, pas isabet oranını kısmen arttıracağı belirtilmiştir. Başka bir çalışmada ise kısa uzunluktaki pasların, uzun uzunluktaki paslardan daha etkili olduğu sonucuna ulaşılmıştır (Tenga vd., 2010b). Jonkovic, Leontijević ve Tomić (2016) yaptıkları bir araştırmada, takımların başarıyla sonuçlanan ataklarında bireysel çözümlerle hazırlanan atakların çoğunun isabetli şutla sonuçlandığını; bunu takiben sırasıyla yanlardan gelen ortalar, derin paslar, oyun yönünü ters yöne çeviren paslar ve kazanılan toplar sonrasında da kaleye çekilen şutların olduğunu tespit etmişlerdir. Modern futbolda hızlı bir şekilde baskı yapabilmek, kompakt savunma anlayışını uygulayabilmek ve gol atmak için başarılı takımlar topa sahip olma oranını önemsemeden topu ileriye doğru taşıyan pasları, geriye ve yana doğru atılan paslardan daha fazla tercih etmişlerdir (Saito vd., 2013).

Çalışmamızın taktik parametre bulgularının sonuçlarına göre ise; ikinci bölgede yapılan top kaybından sonra pres ile üçüncü bölgede topu $0-5 \mathrm{sn}$. içinde geri kazanmak $(\mathrm{p}=0.002)$, birinci bölgedeki top kaybından sonra birinci bölgede 5-10 sn. içinde topu geri kazanmak ( $\mathrm{p}=0.001)$, kendi yarı alanının birinci bölgesinde top kazanıp 0-10 sn. içinde rakip yarı alanına geçmek $(\mathrm{p}=0.001)$, karşı yarı alanın ikinci bölgesinde top kazanıp 0-5 sn. ( $\mathrm{p}=0.023)$, ve 5-10 sn.'de ( $\mathrm{p}=0.049)$ atağı isabetli sonuçlandırmak 
maçlarda başarılı olma kriteri ile anlamlı ilişki içerisindedir. İkinci bölgedeki top kayıplarından sonra, ani defansif geçiş ile önde baskı yaparak, topun 0-5 sn. içinde geri kazanılması atağın sonuçlanmasını sağlar. Birinci bölgede topu kaybedip 5-10 sn. içerisinde geri kazanan ve kendi yarı alanının birinci bölgesinde top kazanıp, 0-10 sn. içinde rakip yarı alanına geçen takımlar, hızlı bir ofansif geçiş ile atak sonuçlandırmaktadırlar. Karşı yarı alan ikinci bölgede top kazanımıyla 0-5 ve 5-10 sn. de yapılan ofansif geçişler, kontra atakların ve isabetli şutla sonuçlanan atakların oluşmasını sağlar.

Literatürde ise; defansif geçişlerin süreleri, başlangıç ve bitiş bölgeleri incelenmiş; defansif geçişlerin $\% 66,3$ ' nün 1 ve 15 sn. arasında sonuçlandığ 1 ve büyük bir kısmının $(\% 48,9) 2$. bölgede (ofansif alan) başlayıp 2. bölgede (defansif alan) sona erdiği rapor edilmiştir (Casal vd., 2016). Bu araştırmanın aksine önceki yıllarda yapılan bir araştırmada, Avrupa' nın en üst düzey takımlarının 2. bölgede kazanılan toplarla atakların gol ile sonuçlandırıldığı görülmüştür (Garganta vd., 1997). Bir diğer araştırma ise, topların topların üçüncü bölgede kazanılarak, penetratif pasların tercih edilmesinin, yerleşik düzende olmayan savunmaya karşı atak sonuçlandırmada ve gol atmada daha etkili olduğunu bildirmiş̧tir (Tenga vd., 2010b).

\section{SONUÇ ve ÖNERİLER}

Sonuç olarak; defansif ve ofansif oyun geçişlerinde 0-5 ve 5-10 sn. içerisinde reaksiyon gösteren, üçüncü bölgede isabetli uzun pas yapan, atakları ceza sahası içerisinde isabetli şutla sonuçlandıran takımlar başarılı sonuçlar alabilmektedirler. $\mathrm{Bu}$ araştırma tasarımında, takımların başarılı ve başarısız maç sonuçları üzerinden veriler toplanarak analiz yapılmıştır. Oyun geçişleri ve oyun stilleri her maçta rakibe göre değişiklik gösterebilir. Bu nedenle, araştıma tasarımını ev sahibi ve rakip takım olacak şekilde düzenleyip, buna göre veri analizi yapmak daha uygulanabilir bilgilerin ortaya çıkmasını sağlayabilir.

\section{PRATIK/SAHA UYGULAMALARI}

Bilgisayar destekli notasyon analizi yapan video analiz programları ile teknik ve taktik parametrelerin analizi zaman almaktadır. Gerçek zamanlı sporcu takibi yapabilen, senkronize çalışan kamera sistemlerinin kullanımıyla zaman kaybının önüne geçilebilir. Ayrıca bu kamera sistemlerinin çoğu, koşu mesafesi, koşu hızı vb. fiziksel parametrelerin verilerini de kullanıcıya sağladığından, karar verme aşamasında daha fazla bilgi edinilmesini sağlayacaktır.

\section{KAYNAKÇA}

Altman, D.G. Practical Guide to Medical Statistics. London: Chapman Hall. 1991; p. 404.

Baca, A. editor. Computer science in sport: research and practice. Routledge; 2014.

Bangsbo, J., \& Peitersen, B. Popular Systems and Styles of Play. In: Strudwick A. Soccer Science. Human Kinetics. 2016; p.433-458.

Bangsbo, J., Mohr, M., \& Krustrup, P. Physical and metabolic demands of training and match-play in the elite football player. Journal of sports sciences. 2006; 24(07):665-74.

Barnes, C., Archer, D., Bush, M., Hogg, R., \& Bradley, P. The evolution of physical and technical performance parameters in the English Premier League. International Journal of Sports Medicine. $2014 ; 35: 1-6$.

Barreira, D., Garganta, J., Guimarães, P., Machado, J., \& Anguera, M.T. Ball recovery patterns as a performance indicator in elite soccer. Proceedings of the Institution of Mechanical Engineers, Part P: Journal of Sports Engineering and Technology. 2014; 228(1):61-72.

Bradley, P.S., Sheldon, W., Wooster, B., Olsen, P., Boanas, P., \& Krustrup, P. High-intensity running in English FA Premier League soccer matches. Journal of sports sciences. 2009; 27(2):159-68.

Carling, C., Williams, A.M., \& Reilly, T. Handbook of soccer match analysis: A systematic approach to improving performance. London: Routledge. 2005.

Casal, C.A., Andujar, M.Á., Losada, J.L., Ardá, T., \& Maneiro, R. Identification of Defensive Performance Factors in the 2010 FIFA World Cup South Africa. Sports. 2016; 4(4):54.

Coutts, A.J. Evolution of football match analysis research. Journal of sports sciences. 2014.

De Baranda, P.S., \& Lopez-Riquelme, D. Analysis of corner kicks in relation to match status in the 2006 World Cup. European Journal of Sport Science. 2012; 12(2):121-9.

Franks, I.M., \& Miller, G. Eyewitness testimony in sport. Journal of sport behavior. 1986; 9(1):38.

Garganta, J., Maia, J., \& Basto F. Analysis of goal-scoring patterns in European top level soccer teams. Science and football III. 1997:246-50. 
Hughes, M., \& Churchill, S. Attacking profiles of successful and unsuccessful teams in Copa America 2001. In Science and football V: The proceedings of the fifth world congress on science and football 2005; p. 222-228.

Hughes, M., \& Franks, I. Analysis of passing sequences, shots and goals in soccer. Journal of sports sciences. 2005; 23(5):509-14.

Janković, A., Leontijević, B., \& Tomić, L. Attacks of the soccer teams participating in the champions league and the Serbian super liga. Fizička kultura. 2016; 70(1):80-7.

Jones, P.D., James, N., \& Mellalieu, S.D. Possession as a performance indicator in soccer. International Journal of Performance Analysis in Sport. 2004; 4(1):98-102.

Lago-Peñas, C., Lago-Ballesteros, J., \& Rey, E. Differences in performance indicators between winning and losing teams in the UEFA Champions League. Journal of Human Kinetics. 2011; 27:135-46.

Laird, P., \& Waters, L. Eyewitness recollection of sport coaches. International Journal of Performance Analysis in Sport. 2008; 8(1):76-84.

Liu, H., Hopkins, W., Gómez, A.M., \& Molinuevo, S.J. Inter-operator reliability of live football match statistics from OPTA Sportsdata. International Journal of Performance Analysis in Sport. 2013; 13(3):803-21.

Maslovat, D., \& Franks, I.M. 'The need for feedback'. In: Hughes M, Franks IM, editors. The Essentials of Performance Analysis: An Introduction. London: Routledge. 2008; p. 1-7.

Mohr, M., Krustrup, P., \& Bangsbo, J. Match performance of high-standard soccer players with special reference to development of fatigue. Journal of sports sciences. 2003; 21(7):519-28.

Muhamad, S., Norasrudin, S., \& Rahmat, A. Differences in goal scoring and passing sequences between winning and losing team in UEFA-EURO Championship 2012. World Academy of Science, Engineering and Technology (74). 2013: 118-23.

Saito, K., Yoshimura, M., \& Ogiwara, T. Pass appearance time and pass attempts by teams qualifying for the second stage of FIFA World Cup 2010 in South Africa. Football Science. 2013; 10:65-9.

Scoulding, A., James, N., \& Taylor, J. Passing in the Soccer World Cup 2002. International Journal of Performance Analysis in Sport. 2004; 4(2):36-41.

Tenga, A., Holme, I., Ronglan, L.T., \& Bahr, R. Effect of playing tactics on achieving score-box possessions in a random series of team possessions from Norwegian professional soccer matches. Journal of sports sciences. 2010a; 28(3):245-55.

Tenga, A., Holme, I., Ronglan, L.T., \& Bahr, R. Effect of playing tactics on goal scoring in Norwegian professional soccer. Journal of Sports Sciences. 2010b; 28(3):237-44.

Vogelbein, M., Nopp, S., \& Hökelmann, A. Defensive transition in soccer-are prompt possession regains a measure of success? A quantitative analysis of German Fußball-Bundesliga 2010/2011. Journal of sports sciences. 2014; 32(11):1076-83.

\section{CITATION OF THIS ARTICLE}

Yıldız, M., Demirarar, O., Canüzmez, A.E., \& Özçaldıran, B. (2021) UEFA 2016 Avrupa Futbol Şampiyonasındaki Şutların Pasların ve Oyun Geçişlerinin Analizi. International Journal of Sport, Exercise \& Training Sciences - IJSETS, 7(3), 92-99. Doi: 10.18826/useeabd.930133 